\title{
ANALYSING VOLATILITY IN EQUITY INDICES - A MARKOV APPROACH FOR BOTSWANA DOMESTIC COMPANY INDICES
}

\author{
K.S. Madhava Rao*and K.K. Moseki \\ Department of Statistics \\ University of Botswana, Gaborone \\ raom@mopipi.ub.bw, mosekikk@mopipi.ub.bw
}

\begin{abstract}
In financial economics, forecasting volatility in stock indices and currency returns has received considerable attention in the last two decades. Many traditional econometric methods forecast asset returns by a point prediction of volatility. The central contribution of this paper is to suggest an alternative approach for modelling and related analysis of asset returns. In this approach, the volatility in stock returns is defined in terms of categories depending on the mean of stock returns and its standard error. This classification naturally allows the study of volatility in terms of a Markov model. The approach suggested here will be of interest to academics, stock market investors, and analysts.
\end{abstract}

\section{OPSOMMING}

Op die terrein van die finansiële ekonomie het die vooruitskatting van volatiliteit in die aandeelindekse en wisselkoerse baie aandag getrek oor die afgelope twee dekades. Verskeie tradisionele ekonometriese vooruitskattingsmodelle baseer die vooruitskatting van opbrengste op ' $n$ puntvooruitskatting van die wisselvalligheid. Die bydrae van hierdie artikel is om ' $n$ alternatiewe metode voor te stel vir die modellering. Volgens die model word die volatiliteit van opbrengste gekategoriseer op grond van die gemiddelde opbrengste en die standaardfout. Dit skep geleetheid vir die toepassing van ' $n$ Markov-model. Die model sal akademici, beleggers en analiste interesseer.

"Corresponding author 


\section{INTRODUCTION}

The analysis of equity prices/indices has been a well-researched problem for business, economics, and financial analysts in the last few decades. It has captured the fancy of financial economists and ordinary trading persons alike. There have been several approaches to analysing equity prices/indices data. Notable among these, from a statistical point of view, were those based on the theories of multiple regression and time series analysis.

It is well known that daily equity prices are subject to random shocks inherent in any market environment. The effect of random shock is unpredictable, in that the equity price may show an upward or downward trend on a day-to-day basis. Further, besides the direction of movement, the magnitude of swing is also of considerable interest in stock market analysis. In a stock market trade, typically there are two types of players: a buyer and a seller, and they could be either an individual or an institution. The objectives of a buyer or a seller operating in a stock market could be either short-term or long-term gain. 'Short-term' may mean a few weeks or months, while 'long-term' may refer to a year or more. Needless to say, due to the volatility inherent in a vibrant market, the gain may mean either a profit or a loss. A short-term gain objective, in general, is more speculative than a long-term gain objective. A buyer may trade in the market either to build up his portfolio for long-term management, or to make some 'quick bucks' by releasing his holdings when the market picks up. On the other hand, a seller will primarily be looking for opportunities to sell his holdings when there is an upswing in the market. In equity market trading, a player can have the dual role of buyer and seller.

In this paper we assume that the key player in the market is the seller. As the buyer's interest is the opposite of that of a seller, the methodology developed for seller-oriented market sentiments can be easily modified for buyer-oriented sentiments.

It is believed that equity prices often exhibit the phenomenon of volatility clustering - that is, periods in which their prices show wide swings for an extended time lasting days, weeks, or months. Knowledge of volatility is crucially important in many areas. Investors in equity markets are obviously interested in the volatility of equity prices, for high volatility could mean huge losses or gains, and so greater uncertainty. In a volatile market it is difficult for companies to raise capital.

Forecasts of the distribution of asset returns are of great importance in the context of financial risk management. While many methods have been suggested, the seminal work of Engel [4] and Bollerslev [2], where the single-state Generalized AutoRegressive Conditional Heteroscedasticity (GARCH) model was developed, may be worth mentioning. The GARCH class of models, and subsequent extensions and generalisation of them, essentially dealt with the problem of point prediction of volatility. The central contribution of this paper is that it suggests an alternative approach for modelling and related analysis of asset returns. In the new approach proposed here, we recognise the fact that the volatility in stock returns can be classified into various states according to the predetermined perceptions of the stock player. In this paper, we build a Markov model for volatility states of equity indices. As an application of the proposed model, we analyse Botswana stock market data from 1999-2005. The Markov models are based on weekly and monthly equity indices. The different states of the Markov model are classified, and steady state probabilities are worked out. It is hoped that the approach suggested here will be of interest to both academics and stock market players. While forecasting of equity indices is quite difficult, the reasonably accurate probability model approach suggested in this paper can provide a credible alternative for fund managers and investors to align their policies and strategies.

The rest of the paper is organised as follows. Section 2 will describe a Markov model for equity indices. The rules for generating volatility states, the construction of a transition probability matrix, the classification of states and steady state probabilities, among others, are discussed in this section. Section 3 deals with the application of the proposed model 
and related analysis to Botswana Stock Exchange (BSE) weekly and monthly domestic company indices. Section 4 offers concluding remarks and a few directions for future research.

\section{A MARKOV MODEL FOR EQUITY INDICES}

The applications of Markov chains to a variety of fields, especially in business and the social sciences, have been well established. Notable among these fields are financial economics, agricultural economics, geography, and sociology. In financial economics, studies related to equity price, index of stock and debt, asset returns, and price of option have incorporated the Markov property. These applications have been published in various technical journals. A good treatment of these applications can be found in Bhat [1], Isaacson and Madsen [6], and others.

The study of volatility - the wide swings that are prevalent in daily, weekly, or monthly equity indices - can be approached from the classical point of the discrete-time process. Here we characterise the volatility of the equity indices as its movement from one state to another in a random fashion.

\subsection{Assumptions:}

A.1: The equity index is available for all working days of the stock exchange.

A.2: The equity indices are subject to random shocks due to the market environment.

A.3: The variations in equity indices can be divided into a finite number of states on the basis of some objective rules.

A.4: The equity indices are analysed from the perspective of a seller.

Assumptions A1-A4 are not restrictive, in the sense that they are typically found in every stock market environment. For example, in every stock market the world over, data are recorded not only on a daily basis, but often - more frequently in terms of what is usually called 'tick data'. Quite obviously, movements in equity indices are probabilistic. Next, the variations in equity indices can be factored into various classes depending on the perspectives of the market player. Finally, the two important players in every market are the seller and the buyer.

Let the variable ' $\mathrm{T}$ ' refer to the day and ' $\mathrm{N}$ ' be the total number of days in the study period. Further, let ' $w$ ' denote the week so that ' $\mathrm{W}$ ' corresponds to the total number of weeks. Suppose that we have a time series data of equity indices, $P_{t}, t=1, \ldots, N$. Let ' $\mathrm{n}_{\mathrm{w}}$ ' be the number of trading days in the week ' $w$ '. (Usually $n_{w}=5$, the number of trading days in a typical week during which transactions in equity indices take place in a market.) For the weekly equity indices, a Markov model can be constructed by comparing the average equity index of the current week $\left(\overline{\mathrm{P}}_{\mathrm{w}+1}\right)$ with the average equity index of the previous week $\left(\bar{P}_{w}\right)$. However, a two-state model is too simple, in that the volatility of stock indices cannot be fully captured. A natural question then is, how best can we formulate a classification rule so that different states of volatility can be reflected in time series data of stock indices? Obviously the classification rule cannot be subjective, as it may be devoid of any rational content. We formulate a few possible classification rules below, keeping in mind the need for rationality and objectivity: 


\subsection{A few possible classification rules:}

a) A rule based on 'Action and warning limits':

Let the weekly average equity index for week $w$ be given by

$$
\bar{P}_{w}=\frac{1}{n_{w}} \sum_{t=1}^{n_{w}} P_{t}, w=1,2, \ldots, \mathrm{W}
$$

and the variance of equity index for week $w$ be given by

$$
s_{w}^{2}=\frac{1}{\left(n_{w}-1\right)} \sum_{t=1}^{n_{w}}\left(P_{t}-\bar{P}_{w}\right)^{2}
$$

The market sentiments in a stock market, from the standpoint of a seller, can be generally seen to belong to different categories. We shall assume that these sentiments can be classified into seven distinct categories. Based on this assumption, we may classify the volatility in equity indices for weekly data as follows.

$\mathrm{S}_{1:}$ The depressed / fear sentiment. This is a state where the equity index witnesses a sharp enough fall to cause a seller holding stocks to panic. This may lead to distress selling and shatter investor confidence. This state of sentiment may also witness eventual bankruptcy or consolidation or regulatory intervention. Further, raising funds from the capital market may be adversely affected.

$\mathrm{S}_{2}$ : The bearish sentiment. This is a state where the equity index witnesses a significant enough fall to cause frustration for a seller holding stocks. This may lead to the offloading of stocks and undermine investor confidence. Moreover, raising funds from the capital market may be adversely affected.

$\mathrm{S}_{3}$ : The downward sentiment. This is a state where the equity index witnesses a gradual fall, causing a warning to an investor. This may lead to the offloading of stocks, and may dent investor confidence. Further, raising funds from the capital market may be adversely affected.

$\mathrm{S}_{4}$ : The tranquil sentiment. This is a state where the equity index witnesses normal swings. The investor continues to be an active player in the stock market. This state may also be called 'range bound' or 'uncertain'.

$\mathrm{S}_{5}$ : The upward sentiment. This is a state where the equity index witnesses a gradual upward swing, causing an investor to feel encouraged. Sustained attempts may be needed to raise funds from the capital market.

$\mathrm{S}_{6}$ : The bullish sentiment. This is a state where the equity index witnesses a significant upward swing, giving rise to speculation by a seller holding stocks. Further, raising funds from the capital market may be easy.

$\mathrm{S}_{7}$ : The greed / bubble sentiment. This is a state where the equity index witnesses a sharp rise, prompting a seller either to dispose off his load or to tend to hold on in the hope of further appreciation, leading to a bubble-like condition. This state reassures the seller for having waited until now to make massive gains. Further, raising funds from the capital market may be easy.

In order to reflect the seven market sentiments above, we associate the following classification rules with the states $S_{j}, j=1,2,3,4,5,6,7$. 
For a week $(w+1), w=1,2, \ldots, \mathrm{W}-1$, the equity index is said to belong to

(i) State $S_{1}$, if

$$
\overline{\mathrm{P}}_{\mathrm{w}+1}<P_{w}-3 \frac{s_{w}}{\sqrt{n_{w}}}
$$

(ii) State $S_{2}$, if

$$
\bar{P}_{w}-3 \frac{\mathrm{s}_{\mathrm{w}}}{\sqrt{\mathrm{n}_{\mathrm{w}}}} \leq \overline{\mathrm{P}}_{\mathrm{w}+1}<\bar{P}_{w}-2 \frac{s_{w}}{\sqrt{n_{w}}}
$$

(iii) State $S_{3}$, if

$$
\bar{P}_{w}-2 \frac{s_{w}}{\sqrt{n_{w}}} \leq \overline{\mathrm{P}}_{\mathrm{w}+1}<\bar{P}_{w}-\frac{s_{w}}{\sqrt{n_{w}}}
$$

(iv) State $\mathrm{S}_{4}$, if

$$
\bar{P}_{w}-\frac{s_{w}}{\sqrt{n_{w}}} \leq \overline{\mathrm{P}}_{\mathrm{w}+1}<P_{w,}^{-}+\frac{s_{w}}{\sqrt{n_{w}}}
$$

(v) State $S_{5}$, if

$$
\bar{P}_{w}+\frac{s_{w}}{\sqrt{n_{w}}} \leq \overline{\mathrm{P}}_{\mathrm{w}+1}<\bar{P}_{w}+2 \frac{s_{w}}{\sqrt{n_{w}}}
$$

(vi) State $S_{6}$, if

$$
\bar{P}_{w}+2 \frac{s_{w}}{\sqrt{n_{w}}} \leq \overline{\mathrm{P}}_{\mathrm{w}+1} \leq \bar{P}_{w}+3 \frac{s_{w}}{\sqrt{n_{w}}}
$$

(vii) State $S_{7}$, if

$$
\overline{\mathrm{P}}_{\mathrm{w}+1}>\bar{P}_{w}+3 \frac{s_{w}}{\sqrt{n_{w}}}
$$

In classification rule (3) above, the multipliers \pm 3 and \pm 2 of $s_{w}$ respectively correspond to those used in action and warning limits of statistical process control (see, for example, Grant and Leavenworth [4]). It should be observed that the class of states $S=\left\{S_{1}, S_{2}, S_{3}, S_{4}\right.$, $\left.\mathrm{S}_{5}, \mathrm{~S}_{6}, \mathrm{~S}_{7}\right\}$ suggested here is quite general in the sense that it is capable of reflecting most of the market sentiments usually observed in a vibrant stock market economy. In a less vibrant stock market economy, one may continue to work with smaller set of states - say, for example, $S^{*}=\left\{S_{1}, S_{2}, S_{3}^{*}, S_{6}, S_{7}\right\}$, where the states $S_{3}, S_{4}, S_{5}$ in $S$ are merged to form the state $\mathrm{S}_{3}^{*}\left(\bar{P}_{w}-2 \frac{\mathrm{S}_{\mathrm{w}}}{\sqrt{\mathrm{n}_{\mathrm{w}}}} \leq \overline{\mathrm{P}}_{\mathrm{w}+1}<\bar{P}_{w}+2 \frac{\mathrm{S}_{\mathrm{w}}}{\sqrt{\mathrm{n}_{\mathrm{w}}}}\right)$ in $\mathrm{S}^{*}$. The sentiment expressed by the state $S_{3}^{*}$ may be appropriately named depending on the perception of the seller. For example, state $S_{3}^{*}$ may be called 'range bound' or 'sideways movement' or 'uncertain'. Alternatively one may merge the states $\left(S_{1}, S_{2}\right),\left(S_{6}, S_{7}\right)$ in $S$ to form two new states $\left(S_{1}^{*}, S_{6}^{*}\right)$ along with the states $S_{3}, S_{4}, S_{5}$ in $S$. The new merged states may be respectively called 'bearish sentiment' and 'bullish sentiment'.

\section{b) Rules based on 'probability limits'}

If the market sentiments appear to be uniform over, say, four categories, one may use the states defined on the basis of quartiles. Here the multipliers of $\mathrm{S}_{\mathrm{w}}$ may correspond to the three quartiles of the standard normal distribution $\left(Q_{1}=-0.675, Q_{2}=0, Q_{3}=+0.675\right)$. Accordingly, for a week $(w+1), w=1,2, \ldots, W-1$, the equity index belongs to

(i) State $S_{1}$, if

$$
\begin{aligned}
& \overline{\mathrm{P}}_{\mathrm{w}+1}<\bar{P}_{w}-0.675 \frac{s_{w}}{\sqrt{n_{w}}} \\
& \bar{P}_{w}-0.675 \frac{s_{w}}{\sqrt{n_{w}}} \leq \overline{\mathrm{P}}_{\mathrm{w}+1}<\bar{P}_{w}
\end{aligned}
$$

(ii) State $S_{2}$, if 
(iii) State $S_{3}$, if

$$
\bar{P}_{w} \leq \overline{\mathrm{P}}_{\mathrm{w}+1}<\bar{P}_{w}+0.675 \frac{s_{w}}{\sqrt{n_{w}}}
$$

(iv) State $\mathrm{S}_{4}$, if

$$
\bar{P}_{w}+0.675 \frac{s_{w}}{\sqrt{n_{w}}}<\overline{\mathrm{P}}_{\mathrm{w}+1}
$$

Here the sentiments expressed by the four states may be respectively called 'deep bearishness', 'mild pessimism', 'mild optimism', and exuberant bullishness'.

On the other hand, if in a market there are six sentiments defined, say, by the four equal parts of the middle $40 \%$, and the lower and upper tail consisting of $30 \%$ each of the total variability, one may use the following six states. Here the multipliers of $S_{w}$ correspond to the five deciles, namely $D_{3}$ to $D_{7}$ of the standard normal distribution $\left(D_{3}=-0.525, D_{4}=-\right.$ $\left.0.255, D_{5}=0, D_{6}=+0.255, D_{7}=+0.525\right)$. The classification rule for these six states then would be as follows:

For a week $(w+1), w=1,2, \ldots, W-1$, the equity index belongs to

$$
\begin{array}{ll}
\text { (i) State } \mathrm{S}_{1} \text {, if } & \overline{\mathrm{P}}_{\mathrm{w}+1}<\bar{P}_{w}-0.525 \frac{s_{w}}{\sqrt{n_{w}}} \\
\text { (ii) State } \mathrm{S}_{2} \text {, if } & \bar{P}_{w}-0.525 \frac{s_{w}}{\sqrt{n_{w}}} \leq \overline{\mathrm{P}}_{\mathrm{w}+1}<\bar{P}_{w}-0.255 \frac{s_{w}}{\sqrt{n_{w}}} \\
\text { (iii) State } \mathrm{S}_{3} \text {, if } & \bar{P}_{w}-0.255 \frac{s_{w}}{\sqrt{n_{w}}} \leq \overline{\mathrm{P}}_{\mathrm{w}+1}<\overline{P_{w}} \\
\text { (iv) State } \mathrm{S}_{4} \text {, if } & P_{w} \leq \overline{\mathrm{P}}_{\mathrm{w}+1}<\frac{P_{w}}{\text { (v) State } \mathrm{S}_{5} \text {, if }}+0.255 \frac{s_{w}}{\sqrt{n_{w}}} \\
& P_{w}+0.255 \frac{s_{w}}{\sqrt{n_{w}}} \leq \overline{\mathrm{P}}_{\mathrm{w}+1} \leq \bar{P}_{w}+0.525 \frac{S_{w}}{\sqrt{n_{w}}} \\
\text { (vi) State } \mathrm{S}_{6} \text {, if } & P_{w}+0.525 \frac{s_{w}}{\sqrt{n_{w}}}<\overline{\mathrm{P}}_{\mathrm{w}+1}
\end{array}
$$

In classification rule (5), the possible states may be suitably named depending on market sentiments and investors' perceptions. It may be mentioned that in the rules based on probability limits stated above, we have used quartiles and deciles of standard normal distribution to be multipliers of the standard errors. Alternatively, one may use other standard distributions. Further, in the classification rules (3)-(5), the arithmetic mean and standard deviations are used as measures of location and dispersion. However, one can use, in general, alternative measures of location such as the median, mode, geometric mean, etc, and alternative measures of dispersion like range, mean deviation, etc.

\subsection{A stochastic model for market sentiments}

Once the weekly/monthly equity prices have been classified into different states according to the criteria discussed in the previous section, a natural question that arises is: How best can the volatility movements be captured by a discrete-time process? We assume that the volatility movements are best described by a Markov-like model. It may be pointed out that this assumption in the context of our problem is not too restrictive, as the underlying discrete time-process has the following features of a Markov model:

(i) Volatility states are well-defined by the classification rules (3)-(5) and are therefore mutually exclusive and exhaustive for a given time point. 
(ii) Markov property is satisfied by the classification rules, since the immediate future volatility state of the equity prices depends only on the current weekly/monthly average, but not on its past averages. In fact, this is implied by the construction of the classification rule, as the average $\overline{\mathrm{P}}_{\mathrm{w}+1}$ is compared with $\overline{\mathrm{P}}_{\mathrm{w}} \pm$ a multiplier of standard error of $\overline{\mathrm{P}}_{\mathrm{w}}$.

(iii) Probability of belonging to a state does not change with time; the Markov chain would be stationary.

Next, we proceed to construct the stochastic matrix giving the various transition probabilities of moving from one state to another state. Suppose that we observe a finite Markov chain with $k$ states $(1,2, \ldots, k)$ until $n$ transitions have taken place. Let $n_{i j}$ be the number of transitions from $i$ to $j(i, j=1,2, \ldots, k)$. Let $\sum_{j=1}^{k} n_{i j}=n_{i}$. These transition counts can be represented as

\begin{tabular}{|l|l|l|l|l|l|l|}
\hline & 1 & 2 & $\cdot$ & $\cdot$ & $\cdot$ & $k$ \\
\hline $\mathbf{1}$ & $n_{11}$ & $n_{12}$ & $\cdot$ & $\cdot$ & $\cdot$ & $n_{1 k}$ \\
$\cdot$ & $n_{21}$ & $n_{22}$ & & & & \\
$\cdot$ & $\cdot$ & $\cdot$ & $\cdot$ & $\cdot$ & $\cdot$ & $n_{2 k}$ \\
$\cdot$ & $\cdot$ & $\cdot$ & $\cdot$ & $\cdot$ & $\cdot$ & $\cdot$ \\
$k$ & $n_{k 1}$ & $n_{k 2}$ & & & & $\cdot$ \\
\hline
\end{tabular}

Let $\mathrm{p}_{\mathrm{ij}}, \mathrm{i}, \mathrm{j}=1, \ldots \mathrm{k}$, be the probability of transition from the state $\mathrm{i}$ to state $\mathrm{j}$ and the stationary transition probability matrix (TPM) of the Markov chain be $\mathrm{P}$, given by

$$
P=\left(\begin{array}{cccc}
p_{11} & p_{12} & \cdots & p_{1 k} \\
p_{21} & p_{22} & \cdots & p_{2 k} \\
\cdot & \cdot & \cdot & \cdot \\
\cdot & \cdot & \cdot & \cdot \\
\cdot & \cdot & \cdot & \cdot \\
p_{k 1} & p_{k 2} & \cdots & p_{k k}
\end{array}\right)
$$

Once we estimate the TPM P by $\hat{\mathrm{P}}=\left(\left(\hat{\mathrm{p}}_{\mathrm{ij}}\right)\right), i, j=1,2, \ldots, \mathrm{k}$, we can explore it further for (i) classification of states, (ii) stationary distribution, (iii) recurrence time for state i. For example, the following definition gives the stationary distribution of the Markov chain. 
Definition 2.1. For an irreducible ergodic chain, the limits $\pi_{\mathrm{i}}=\lim _{\mathrm{n} \rightarrow \infty} \mathrm{p}_{\mathrm{ji}}^{(\mathrm{n})}$ exist and are independent of the initial state $j$. The limits $\pi_{\mathrm{i}}$ are such that $\pi_{\mathrm{i}} \geq 0, \sum \pi_{\mathrm{i}}=1$, and the limits define a probability distribution. Furthermore, the limiting probability distribution $\left\{\pi_{i}\right\}$ is identical to the stationary distribution of the given chain, so that

$$
\pi_{\mathrm{i}}=\sum_{\mathrm{j}} \pi_{\mathrm{j}} \mathrm{p}_{\mathrm{ji}}, \sum \pi_{\mathrm{i}}=1
$$

Having found out the limiting distribution of an aperiodic, irreducible k-state Markov chain whose transition probability matrix is $\mathrm{P}$, one may proceed to find the first passage time of the transition $\mathrm{i} \leftrightarrow \mathrm{j}$, in particular the recurrence time for state $\mathrm{i}, \mathrm{i}=1, \ldots \mathrm{k}$. It may be recalled that the expected value of the recurrence time for state $i$ is given by

$$
\tau_{\mathrm{ii}}=\frac{1}{\pi_{\mathrm{i}}}, \mathrm{i}=1, \ldots \mathrm{k}
$$

We refer to Isaacson \& Madsen [5] for a detailed discussion of the conceptual and theoretical issues alluded to in this section.

Next, we shall consider the estimation and a related hypothesis testing problem as applied to finite Markov chains with stationary (time-homogeneous) transition probability matrices.

We are interested in the estimates of the elements $\mathrm{p}_{\mathrm{ij}}$; we shall denote their estimates by

$p_{i j}(i, j=1,2, \ldots, k)$. For a given initial state $i$ and a number of trials $n_{i}$, the sample of transition counts $\left(n_{i 1}, n_{i 2}, \ldots, n_{i k}\right)$ can be considered as a sample of size $n_{i}$ from a multinomial distribution with probabilities $\left(p_{i 1}, p_{i 2}, \ldots, p_{i k}\right)$, such that

$\sum_{j=1}^{k} p_{i j}=1$. Straightforward calculations (see Bhat [1] for details) yield the maximum likelihood estimates given by

$$
\hat{p}_{i j}=\frac{n_{i j}}{n_{i}}, i, j=1,2, \ldots k .
$$

Let $\mathrm{p}_{\mathrm{ij}}^{\mathrm{t}}, \mathrm{t}=1, \ldots, \mathrm{T}$ denote the weekly TPM corresponding to the year $\mathrm{t}$. Then one may hypothesise that weekly market sentiments over the $\mathrm{T}$ years are stationary. In other words, we wish to test the null hypothesis that $\mathrm{H}_{0}: \mathrm{p}_{\mathrm{ij}}^{\mathrm{t}}=\mathrm{p}_{\mathrm{ij}}(\mathrm{t}=1, \ldots, \mathrm{T})$. In a typical market sentiment analysis, there could be several choices for $\mathrm{P}_{\mathrm{ij}}$, - for instance, it is pertinent to ask whether annual weekly/monthly transition probabilities reflect the same behaviour during the entire study period. If so, the data can be pooled to give a single transition count matrix and hence a single set of estimates. A likelihood ratio test statistic for testing $\mathrm{H}_{0}$, - i.e. for testing the stationarity of the transition probability matrix - can be constructed as below. 
Let $p_{i j}^{t}$ be the one-step transition probability of a time-dependent process $X(t)$, such that

$$
p_{i j}^{t}=P[X(t+1)=j \mid X(t)=i]
$$

Let $n_{i j}^{t}$ be the number of transition $i \rightarrow j$ during the $t^{t h}$ transition of a process. For a given initial state $i$, the transition counts $n_{i j}^{t}(t=1,2, \ldots T)$ can be represented as

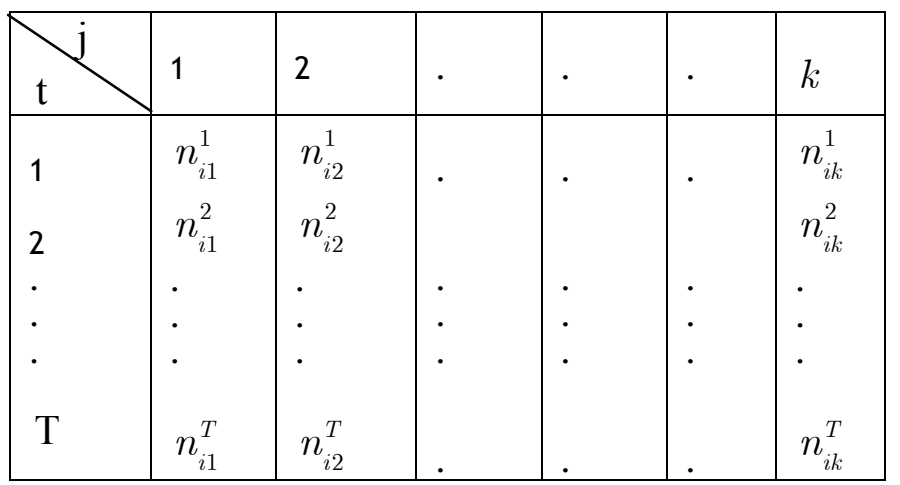

As before, the maximum likelihood estimates of $p_{i j}^{t}$ can be obtained as

$$
\hat{p_{i j}^{t}}=\frac{n_{i j}^{t}}{n_{i}^{t-1}}
$$

where $n_{i}^{t-1}=\sum_{j=1}^{k} n_{i j}^{t}$. Clearly $n_{i}^{t-1}$ is the number of processes in state $i$ at time $t-1$. Suppose we wish to test the hypothesis $H_{0}: p_{i j}^{t}=p_{i j}(t=1,2, \ldots, T)$. Then the maximum likelihood function is given by $f\left(p_{i j}^{t}\right)$, and therefore the likelihood ratio criterion

$$
\Lambda=\frac{f\left(p_{i j}^{t}\right)}{f\left(p_{i j}\right)}
$$

Then it can be shown (see Bhat [1] for details) that, under the null hypothesis $H_{0}$, $-2 \ln \Lambda$ has a $\chi^{2}$ distribution with $(T-1)[k(k-1)]$ degrees of freedom. In this case, 


$$
\begin{aligned}
& -2 \ell n \Lambda=2\left[L\left(p_{i j}^{t}\right)-L\left(\hat{p}_{i j}^{t}\right)\right] \\
& =2 \sum_{\mathrm{t}=1}^{T} \sum_{i=1}^{k} \sum_{j=1}^{k} n_{i j}^{t} \ln \frac{n_{i j}^{t}}{n_{i}^{t-1} p_{i j}} .
\end{aligned}
$$

If some of the $n_{i j}^{t}{ }^{\prime} s$ are zero, then It is assumed that summation in (14) is taken only over $(i, j)$ for which $n_{i j}^{t}>0$. Further, in this case, the degrees of freedom of $\chi^{2}$ distribution will be $(\mathrm{T}-1)[\mathrm{k}(\mathrm{k}-1)]-\mathrm{d}$, where $\mathrm{d}$ is obtained by taking into account the fact that some of the $n_{i j}^{t}$ 's are zero.

\section{APPLICATION TO BOTSWANA DOMESTIC COMPANY INDICES}

One can access the latest share prices from the BSE Market report (http://www.bse.co.bw). The "last" column on the BSE market report indicates the last prevailing price of a particular share. Currently the following are the product offerings of the BSE: equities (found in the domestic, foreign, and venture boards), commercial paper, corporate bonds, and quasi-government bonds.

As before, let us suppose that we have $(\mathrm{W}-1)$ realisations of volatility states corresponding to the given time series of stock prices, consisting of $W$ weeks. Let $n_{i, j}, i, j=1,2,3,4,5$ be the number of transitions from state ' $\mathrm{i}$ ' to state ' $\mathrm{j}$ ' and $\mathrm{n}_{\mathrm{i}}=\sum_{j=1}^{k} n_{i j}$ be the total number of times the process visits the state $\mathfrak{i}, \mathrm{i}=1, \ldots, \mathrm{k}$. Clearly, $\sum_{i=1}^{k} n_{i}=\mathrm{W}-2$. Then, the estimates of $\mathrm{p}_{\mathrm{ij}}$, the transition probabilities from state ' $\mathrm{i}$ ' to state ' $\mathrm{j}$ ' is given by $\hat{\mathrm{p}}_{\mathrm{ij}}=\frac{n_{i j}}{n_{i}}, \quad i, j=1,2, \ldots, k$.

\subsection{Analysis of weekly $\mathrm{DCl}$ data}

The basic data to be considered here refer to the daily domestic company indices (DCI) of the Botswana Stock Exchange for the period 11 January 1999 to 1 December 2005. These data were obtained from Botswana stockbrokers. For the purpose of weekly analysis, the data are clustered into 364 weeks, where each week consists of 5 working days, Monday through Friday. The movements in the $\mathrm{DCl}$ are classified into the seven states $\mathrm{S}_{1}, \mathrm{~S}_{2}, \ldots, \mathrm{S}_{7}$ based on the 'action and warning limits' described by (3). The sequence of states generated by the classification rule (3) for the weekly data can be tabulated, and so the transition probabilities can be constructed in a routine manner. For instance, for the sequence of states generated using the classification rule (3), it can be shown that $\mathrm{n}_{1}=68, \mathrm{n}_{3}=21, \mathrm{n}_{7}=169, \mathrm{n}_{11}=26, \mathrm{n}_{33}=0, \mathrm{n}_{76}=16$ so that estimates of the corresponding transition probabilities are $\hat{p}_{11}=\frac{26}{68}, \hat{p}_{33}=\frac{0}{21}=0, \hat{p}_{76}=\frac{16}{169}$ and so on. The details are omitted, and can be obtained from the authors. Thus we have for the weekly data the estimated transition probability matrix, given by 


$$
\hat{\mathrm{P}}=\left(\hat{\mathrm{p}_{\mathrm{ij}}}\right)=\left(\begin{array}{ccccccc}
26 / 68 & 7 / 68 & 8 / 68 & 8 / 68 & 2 / 68 & 1 / 68 & 16 / 68 \\
4 / 15 & 2 / 15 & 0 & 1 / 15 & 3 / 15 & 1 / 15 & 4 / 15 \\
9 / 21 & 2 / 21 & 0 & 1 / 21 & 3 / 21 & 2 / 21 & 4 / 21 \\
7 / 30 & 3 / 30 & 4 / 30 & 2 / 30 & 2 / 30 & 1 / 30 & 11 / 30 \\
6 / 36 & 1 / 36 & 1 / 36 & 2 / 36 & 5 / 2 & 2 / 36 & 19 / 36 \\
3 / 24 & 0 & 2 / 24 & 3 / 24 & 0 & 1 / 24 & 15 / 24 \\
11 / 169 & 0 & 6 / 169 & 13 / 169 & 23 / 169 & 16 / 169 & 100 / 169
\end{array}\right)
$$

Then, following the standard computations (see, for example, Isaacson \& Madsen [5]), it can be seen that the transition probability matrix given by (15) is (i) irreducible, (ii) persistently non-null, and (iii) aperiodic. Thus, using the definition of ergodicity, it follows that the Markov chain with the transition probability matrix $\hat{\mathrm{P}}$ is ergodic. Further, using the definition 2.1 , we can construct the stationary probability distribution $\left\{\pi_{i}, i=1, \ldots, 7\right\}$

corresponding to the Markov chain $\mathrm{P}$, and using the routine algebraic method, it can be shown that

$$
\begin{aligned}
& \pi_{1}=0.1795, \pi_{2}=0.0405, \pi_{3}=0.0572, \pi_{4}=0.0822, \pi_{5}=0.1054, \pi_{6}=0.0665, \\
& \pi_{7}=0.4686 \text {. }
\end{aligned}
$$

These probabilities essentially refer to the long-term behaviour of the market sentiments, provided that the market is operated under the same conditions. For example, $\pi_{1}=0.1795$ implies that the market sentiment is going to be 'depressed' in about $18 \%$ of the total of 52 weeks (that is, in 9 weeks), $\pi_{2}=0.0405$ implies that the market sentiment is going to be 'bearish' in about $4 \%$ of the total of 52 weeks ( 2 weeks), and so on.

Alternatively, using the result (8), the expected recurrence time $\tau_{\mathrm{ii}}, \mathrm{i}=1, \ldots 7$, in weeks for the seven states $S_{1}, \ldots, S_{7}$ is respectively given by $\tau_{11}=5.57, \tau_{22}=24.67, \tau_{33}=17.48$, $\tau_{44}=12.17, \tau_{55}=9.49, \tau_{66}=15.04, \tau_{77}=2.13$. For example, it may be interpreted that during the period 11 January 1999 to 1 December 2005, the DCl bounced back to state $\mathrm{S}_{7}$ once in every 2.13 weeks, to state $\mathrm{S}_{1}$ once in every 5.57 weeks, and so on.

Next, to see if the weekly TPMs are the same over the seven years under consideration, we use the test statistic given by (14). The sequence of states generated by the classification rule (3) for the weekly data leads to the following transition counts matrices for the years 1999-2005, while the pooled transition count matrix is obtained by adding the corresponding elements of the transition counts matrices of the years 1999-2005. 


\section{Year 1999}

$\left[\begin{array}{lllllll}1 & 1 & 2 & 1 & 0 & 0 & 4 \\ 2 & 2 & 0 & 0 & 1 & 1 & 0 \\ 1 & 1 & 0 & 0 & 0 & 0 & 0 \\ 2 & 2 & 0 & 1 & 0 & 0 & 1 \\ 1 & 0 & 0 & 1 & 0 & 0 & 2 \\ 1 & 0 & 0 & 0 & 0 & 0 & 4 \\ 1 & 0 & 0 & 3 & 4 & 3 & 7\end{array}\right]$

Year 2001

$\left[\begin{array}{ccccccc}2 & 0 & 0 & 0 & 1 & 0 & 0 \\ 0 & 0 & 0 & 0 & 0 & 0 & 0 \\ 1 & 0 & 0 & 0 & 0 & 0 & 0 \\ 0 & 0 & 0 & 0 & 0 & 0 & 1 \\ 1 & 0 & 0 & 0 & 0 & 0 & 4 \\ 0 & 0 & 0 & 0 & 0 & 0 & 0 \\ 2 & 0 & 0 & 1 & 4 & 0 & 30\end{array}\right]$

Year 2003

$\left[\begin{array}{lllllll}8 & 0 & 2 & 2 & 0 & 1 & 1 \\ 0 & 0 & 0 & 0 & 0 & 1 & 0 \\ 1 & 0 & 0 & 0 & 1 & 1 & 2 \\ 0 & 0 & 0 & 0 & 1 & 0 & 2 \\ 0 & 1 & 1 & 0 & 2 & 1 & 2 \\ 1 & 0 & 1 & 0 & 0 & 0 & 3 \\ 3 & 0 & 1 & 1 & 2 & 2 & 6\end{array}\right]$

Year 2005

$\left[\begin{array}{ccccccc}0 & 0 & 0 & 0 & 0 & 0 & 0 \\ 0 & 0 & 0 & 0 & 0 & 0 & 0 \\ 0 & 0 & 0 & 0 & 0 & 0 & 1 \\ 0 & 0 & 0 & 0 & 0 & 0 & 5 \\ 0 & 0 & 0 & 0 & 0 & 0 & 3 \\ 0 & 0 & 0 & 1 & 0 & 0 & 2 \\ 0 & 0 & 1 & 4 & 3 & 2 & 28\end{array}\right]$
Year 2000

$\left[\begin{array}{lllllll}6 & 2 & 0 & 2 & 0 & 0 & 3 \\ 1 & 0 & 0 & 0 & 0 & 0 & 1 \\ 2 & 0 & 0 & 1 & 1 & 0 & 1 \\ 2 & 0 & 3 & 1 & 0 & 0 & 0 \\ 1 & 0 & 0 & 1 & 0 & 1 & 1 \\ 1 & 0 & 0 & 0 & 0 & 1 & 4 \\ 0 & 0 & 2 & 1 & 3 & 4 & 4\end{array}\right]$

Year 2002

$\left[\begin{array}{ccccccc}6 & 3 & 1 & 1 & 0 & 0 & 4 \\ 1 & 0 & 0 & 0 & 1 & 0 & 1 \\ 2 & 0 & 0 & 0 & 0 & 1 & 0 \\ 2 & 0 & 1 & 0 & 0 & 0 & 1 \\ 1 & 0 & 0 & 0 & 1 & 0 & 1 \\ 0 & 0 & 0 & 2 & 0 & 0 & 1 \\ 3 & 0 & 1 & 1 & 1 & 2 & 11\end{array}\right]$

\section{Year 2004}

$\left[\begin{array}{ccccccc}2 & 1 & 3 & 2 & 1 & 0 & 1 \\ 0 & 0 & 0 & 0 & 0 & 0 & 2 \\ 1 & 1 & 0 & 0 & 1 & 0 & 0 \\ 1 & 1 & 0 & 0 & 0 & 0 & 1 \\ 3 & 0 & 0 & 0 & 1 & 0 & 5 \\ 1 & 0 & 0 & 0 & 0 & 0 & 1 \\ 1 & 0 & 0 & 1 & 6 & 2 & 11\end{array}\right]$

Pooled transition counts

(16)

$\left[\begin{array}{ccccccc}25 & 7 & 8 & 8 & 2 & 1 & 16 \\ 4 & 2 & 0 & 3 & 3 & 1 & 4 \\ 8 & 2 & 0 & 1 & 3 & 2 & 4 \\ 7 & 3 & 4 & 2 & 1 & 0 & 11 \\ 7 & 1 & 1 & 2 & 4 & 2 & 18 \\ 4 & 0 & 1 & 3 & 0 & 1 & 15 \\ 10 & 0 & 5 & 12 & 23 & 15 & 97\end{array}\right]$


The estimate of the pooled TPM is given by

$$
\hat{\mathrm{P}}=\left(\hat{\mathrm{p}_{\mathrm{ij}}}\right)=\left[\begin{array}{ccccccc}
25 / 67 & 7 / 67 & 8 / 67 & 8 / 67 & 2 / 67 & 1 / 67 & 16 / 67 \\
4 / 17 & 2 / 17 & 0 & 3 / 17 & 3 / 17 & 1 / 17 & 4 / 17 \\
8 / 20 & 2 / 20 & 0 & 1 / 20 & 3 / 20 & 2 / 20 & 4 / 20 \\
7 / 28 & 3 / 28 & 4 / 28 & 2 / 28 & 1 / 28 & 0 & 11 / 28 \\
7 / 35 & 1 / 35 & 1 / 35 & 2 / 35 & 4 / 35 & 2 / 35 & 18 / 35 \\
4 / 24 & 0 & 1 / 24 & 3 / 24 & 0 & 1 / 24 & 15 / 24 \\
10 / 97 & 0 & 5 / 97 & 12 / 97 & 23 / 97 & 15 / 97 & 97 / 97
\end{array}\right]
$$

Finally, the application of the likelihood ratio test statistic (14) leads to

$$
-2 \ln \Lambda=216.095
$$

which, under the null hypothesis of stationarity, has a $\chi^{2}$ distribution with 69 d.f. The degrees of freedom is obtained by noting that, under the alternative hypothesis, the number of parameters to be estimated is 105, while under the null hypothesis, the parameter to be estimated is 36 . From the table of $\chi^{2}$ distribution, we get

$$
P\left(\chi^{2} \geq 216.095\right)<0.005
$$

This shows that we cannot accept the hypothesis of stationarity of the market sentiments over the seven years, even with $0.5 \%$ significance level. Going back to the problem, we may conclude that the pattern of weekly market sentiments over the seven years 1999-2005 does not remain the same. The practical significance of this finding is that the monthly movements in market sentiments appear to be volatile.

\subsection{Analysis of monthly $\mathrm{DCl}$ data}

In this section, we analyse the monthly $\mathrm{DCl}$. As in the case of weekly data, we construct the estimated transition probability matrix for the seven states Markov model. The basic data to be considered continue to be the same - i.e., the DCl for the period 11 January 1999 to 1 December 2005. The data are clustered into 84 months, each month consisting of 20-22 trading days. The monthly averages and variances are computed using (1) and (2) The movements in $\mathrm{DCl}$ are classified into the seven states $\mathrm{S}_{1}, \mathrm{~S}_{2}, \ldots, \mathrm{S}_{7}$ based on the 'action and warning limits' described by (3). The sequence of states generated by the classification rule (3) can be constructed as noted earlier, and the corresponding transition probability matrix is given by

$$
\hat{\mathrm{P}}=\left(\hat{\mathrm{p}}_{\mathrm{ij}}\right)=\left(\begin{array}{ccccccc}
8 / 17 & 3 / 17 & 1 / 17 & 1 / 17 & 0 & 0 & 4 / 17 \\
1 / 4 & 0 & 0 & 0 & 1 / 4 & 0 & 2 / 4 \\
0 & 0 & 0 & 0 & 0 & 0 & 1 \\
1 & 0 & 0 & 0 & 0 & 0 & 0 \\
1 / 2 & 0 & 0 & 1 / 2 & 0 & 0 & 0 \\
0 & 0 & 0 & 0 & 0 & 0 & 1 \\
5 / 53 & 2 / 53 & 0 & 0 & 1 / 53 & 1 / 53 & 44 / 53
\end{array}\right)
$$


Once again, using definition 2.1 and straightforward computations yield $\pi_{1}=0.2202, \pi_{2}=0.0629, \pi_{3}=0.0130, \pi_{4}=0.0268, \pi_{5}=0.0278, \pi_{6}=0.0120$ and $\pi_{7}=0.6374$.

The expected recurrence time in months for the seven states, $\mathrm{S}_{1}, \ldots, \mathrm{S}_{7}$ is given by $\tau_{11}=4.54, \quad \tau_{22}=15.90, \quad \tau_{33}=76.93, \quad \tau_{44}=37.31, \quad \tau_{55}=35.97, \quad \tau_{66}=83.33$, and $\tau_{77}=1.57$. For example, it may be interpreted that during the period 11 January 1999 to 1 December 2005, the $\mathrm{DCl}$, while in State $\mathrm{S}_{7}$, bounced back to itself once in every 1.57 months, and while in state $\mathrm{S}_{1}$ bounced back to itself once in every 4.54 months, and so on.

Next, to check whether the monthly TPMs are the same for the seven years under consideration, we use the test statistic given by (14). The monthly transition counts matrices for the years 1999-2005, the pooled transition count matrix, and the estimated pooled TPM are given below:

\section{Year 1999}

$\left[\begin{array}{lllllll}1 & 1 & 0 & 0 & 0 & 0 & 1 \\ 0 & 0 & 0 & 0 & 0 & 0 & 1 \\ 0 & 0 & 0 & 0 & 0 & 0 & 0 \\ 0 & 0 & 0 & 0 & 0 & 0 & 0 \\ 0 & 0 & 0 & 0 & 0 & 0 & 0 \\ 0 & 0 & 0 & 0 & 0 & 0 & 0 \\ 2 & 0 & 0 & 0 & 0 & 0 & 4\end{array}\right]$

Year 2001

\section{Year 2000}

$\left[\begin{array}{lllllll}3 & 0 & 0 & 0 & 0 & 0 & 1 \\ 1 & 0 & 0 & 0 & 0 & 0 & 0 \\ 0 & 0 & 0 & 0 & 0 & 0 & 0 \\ 0 & 0 & 0 & 0 & 0 & 0 & 0 \\ 0 & 0 & 0 & 0 & 0 & 0 & 0 \\ 0 & 0 & 0 & 0 & 0 & 0 & 1 \\ 1 & 1 & 0 & 0 & 0 & 1 & 2\end{array}\right]$

\section{Year 2002}

$\left[\begin{array}{lllllll}0 & 0 & 0 & 0 & 0 & 0 & 0 \\ 0 & 0 & 0 & 0 & 0 & 0 & 0 \\ 0 & 0 & 0 & 0 & 0 & 0 & 0 \\ 0 & 0 & 0 & 0 & 0 & 0 & 0 \\ 0 & 0 & 0 & 0 & 0 & 0 & 0 \\ 0 & 0 & 0 & 0 & 0 & 0 & 0 \\ 0 & 0 & 0 & 0 & 0 & 0 & 11\end{array}\right] \quad\left[\begin{array}{lllllll}2 & 1 & 0 & 0 & 0 & 0 & 1 \\ 0 & 0 & 0 & 0 & 1 & 0 & 0 \\ 0 & 0 & 0 & 0 & 0 & 0 & 0 \\ 0 & 0 & 0 & 0 & 0 & 0 & 0 \\ 1 & 0 & 0 & 0 & 1 & 0 & 0 \\ 0 & 0 & 0 & 0 & 0 & 0 & 0 \\ 1 & 0 & 0 & 0 & 0 & 0 & 3\end{array}\right]$ 


$\left[\begin{array}{lllllll}2 & 0 & 1 & 1 & 0 & 0 & 0 \\ 0 & 0 & 0 & 0 & 0 & 0 & 0 \\ 0 & 0 & 0 & 0 & 0 & 0 & 1 \\ 1 & 0 & 0 & 0 & 0 & 0 & 0 \\ 1 & 0 & 0 & 0 & 0 & 0 & 0 \\ 0 & 0 & 0 & 0 & 0 & 0 & 0 \\ 0 & 0 & 0 & 0 & 0 & 0 & 4\end{array}\right] \quad\left[\begin{array}{lllllll}0 & 1 & 0 & 0 & 0 & 0 & 0 \\ 0 & 0 & 0 & 0 & 0 & 0 & 1 \\ 0 & 0 & 0 & 0 & 0 & 0 & 0 \\ 0 & 0 & 0 & 0 & 0 & 0 & 0 \\ 0 & 0 & 0 & 0 & 0 & 0 & 0 \\ 0 & 0 & 0 & 0 & 0 & 0 & 0 \\ 1 & 1 & 0 & 0 & 0 & 0 & 7\end{array}\right]$

\section{Year 2005}

\section{Pooled transition counts}

$\left[\begin{array}{lllllll}0 & 0 & 0 & 0 & 0 & 0 & 0 \\ 0 & 0 & 0 & 0 & 0 & 0 & 0 \\ 0 & 0 & 0 & 0 & 0 & 0 & 1 \\ 0 & 0 & 0 & 0 & 0 & 0 & 0 \\ 0 & 0 & 0 & 0 & 0 & 0 & 0 \\ 0 & 0 & 0 & 0 & 0 & 0 & 0 \\ 0 & 0 & 0 & 0 & 0 & 0 & 9\end{array}\right]$

$\left[\begin{array}{lllllll}8 & 3 & 1 & 1 & 0 & 0 & 3 \\ 1 & 0 & 0 & 0 & 1 & 0 & 2 \\ 0 & 0 & 0 & 0 & 0 & 0 & 2 \\ 1 & 0 & 0 & 0 & 0 & 0 & 0 \\ 2 & 0 & 0 & 0 & 1 & 0 & 0 \\ 0 & 0 & 0 & 0 & 0 & 0 & 1 \\ 5 & 2 & 0 & 0 & 0 & 1 & 40\end{array}\right]$

\section{Estimated pooled TPM}

$$
\hat{\mathrm{P}}=\left(\hat{\mathrm{p}}_{\mathrm{ij}}\right)=\left(\begin{array}{ccccccc}
8 / 16 & 3 / 16 & 1 / 16 & 1 / 16 & 0 & 0 & 3 / 16 \\
1 / 4 & 0 & 0 & 0 & 1 / 4 & 0 & 2 / 4 \\
0 & 0 & 0 & 0 & 0 & 0 & 1 \\
1 & 0 & 0 & 0 & 0 & 0 & 0 \\
21 / 3 & 0 & 0 & 0 & 1 / 3 & 0 & 0 \\
0 & 0 & 0 & 0 & 0 & 0 & 1 \\
5 / 48 & 2 / 48 & 0 & 0 & 0 & 1 / 48 & 40 / 48
\end{array}\right)
$$

The likelihood ratio test statistic (14) leads to

$$
-2 \ln \Lambda=43.80
$$

which, under the null hypothesis of stationarity, has a $\chi^{2}$ distribution with $28-13=15$ d.f. From $\chi^{2}$ tables, we find

$$
\mathrm{P}\left(\chi^{2} \geq 43.80\right)<0.005
$$

Once again this suggests that the pattern of monthly market sentiments over the seven years under consideration does not remain the same. Interestingly, this finding is similar to the conclusion obtained about the stationarity of weekly market sentiments. 


\section{DISCUSSION AND CONCLUSIONS}

It is well-known that in an equity market the equity indices are continuously subject to variations. There are players in the equity market who want to profit-trade with equity indices. A judicious profit-trade requires a fair understanding of the volatility present in the movement of equity indices. While the volatility can been seen in daily, weekly, monthly, or quarterly historical equity indices, its study becomes quite challenging from the point of view of an investor in the stock market. It is imperative to accept that any investment decision based on the daily movement of equity indices is highly speculative; decisions based on the analysis of weekly, monthly, or quarterly movements may help the investor, as it could be argued that some degree of predictable regularity may be witnessed in such equity indices. Our focus in this paper is thus to analyse weekly and monthly equity indices.

In this paper we have proposed a relatively new method by which equity indices can be analysed by constructing some simple classification rules and further assuming a Markov chain model based on these classification rules. The classification rules are so framed that the variations inherent in any financial data can be identified in terms of perceptible states suitability defined. The Markov chain summarises the movement of the variations in the equity indices from one state to another in terms of estimated probability. The methodology developed in this paper has been applied to weekly and monthly Botswana domestic company indices.

We can now summarise our general findings:

(1) Based on one of the rules of classification of states of volatility sentiments discussed in this paper, it is seen that the market environment vis-à-vis the weekly DCl is investorfriendly, as the long-term probability related to the 'greedy' volatility sentiment is quite high and is close to 0.5 . Further, the market environment vis-à-vis the monthly $\mathrm{DCl}$ is even more investor-friendly, as the long-term probability related to the 'greedy' volatility sentiment is close to 0.64 . Therfore, it may be suggested that monthly trading in the $\mathrm{DCl}$ is a better option than weekly trading.

(2) Among the seven market sentiments proposed in this paper, the 'greedy' market sentiment has the smallest estimated recurrence time across weekly and monthly $\mathrm{DCl}$ analysis.

(3) Finally, the analysis based on both weekly and monthly $\mathrm{DCl}$ reveals that the history of transition from one sentiment to another varies from year to year.

The approach suggested here will be of interest to a variety of disciplines in which a phenomenon of interest is observed on a daily basis, and in which one is interested in different states of perceptible variability, measured on the basis of a week, fortnight, month, and so on. Interest rates, currency returns, assembly line production, and so on, readily lend themselves to a similar type of analysis.

\section{REFERENCES}

[1] Bhat, N.U. 1972. Elements of applied stochastic processes. John Wiley \& Sons, Inc., New York.

[2] Bollerslev, T.A. 1987. A conditional heteroscedastic time series model for speculative prices and rates of return. Review of Economics and Statistics, Vol. 69, pp. 542-547.

[3] Casella, G. \& Berger, R.L. 2002. Statistical inference. Duxbury, United Kingdom.

[4] Engel, R.F. 1982. Autoregressive conditional heteroscedasticity with estimates of the variance of United Kingdom inflation. Econometrica, Vol. 50, pp. 987-1007.

[5] Grant, E.L. \& Leavenworth, R.S. 1980. Statistical quality control. McGraw-Hill, New York.

[6] Isaacson, D.L. \& Madsen, R.W. 1976. Markov chains theory and applications. John Wiley \& Sons, London. 